\title{
Increased levels of glycosylated hemoglobin, microalbuminuria and serum cystatin $C$ predict adverse outcomes in high-risk pregnancies with gestational diabetes mellitus
}

\author{
HONGMEI JIN
}

Department of Obstetrics, Qingpu Branch, Zhongshan Hospital Affiliated to Fudan University, Shanghai 201700, P.R. China

Received September 6, 2018; Accepted April 5, 2019

DOI: $10.3892 /$ etm.2019.8336

\begin{abstract}
In the present study, the predictive value of glycosylated hemoglobin (HbA1c), microalbuminuria (24 h mAlb) and serum cystatin $\mathrm{C}$ (Cys-C) levels on the outcome of pregnancy in patients with gestational diabetes mellitus (GDM) was investigated. Samples of 144 females with GDM and 117 normal pregnant females as controls were selected for retrospective analysis. The following parameters were compared between the two groups: Levels of HbA1c, Cys-C and $24 \mathrm{~h} \mathrm{mAlb}$, maternal pregnancy outcome and adverse pregnancy rate. The predictive value of elevated $24 \mathrm{~h} \mathrm{mAlb}$, $\mathrm{HbAlc}$ and Cys-C regarding an adverse pregnancy outcome was then determined. Cys-C, $24 \mathrm{~h} \mathrm{mAlb}$ and HbAlc levels in the GDM group were significantly higher than those in the control group $(\mathrm{P}<0.001)$. The adverse pregnancy rate in the GDM group was significantly higher than that in the control group (40.97 vs. $16.24 \%$; $\mathrm{P}<0.001$ ). Logistic regression and receiver operating characteristics (ROC) analyses indicated that, in subjects with GDM, HbA1c, Cys-C and $24 \mathrm{~h}$ mAlb levels were closely associated with adverse pregnancy outcomes $(\mathrm{P}<0.050)$ and may be considered as predictors for an adverse pregnancy outcome (risk ratio $>1$ ). Linear correlation analyses indicated that $\mathrm{HbAlc}, \mathrm{Cys}-\mathrm{C}$ and $24 \mathrm{~h} \mathrm{mAlb}$ were negatively correlated with the neonatal Apgar scores $(\mathrm{r}=-0.509$, -0.954 and -0.954 , respectively; $\mathrm{P}<0.001)$. According to ROC analysis, the combined predictive sensitivity of HbAlc, Cys-C and $24 \mathrm{~h} \mathrm{mAlb}$ for adverse pregnancy outcome in patients with GDM was $96.49 \%$ and the specificity was $77.19 \%$. The increase in HbAlc, Cys-C and $24 \mathrm{~h}$ mAlb levels is expected to be an effective predictor of adverse pregnancy outcomes in high-risk pregnant women.
\end{abstract}

Correspondence to: Dr Hongmei Jin, Department of Obstetrics, Qingpu Branch, Zhongshan Hospital Affiliated to Fudan University, 1158 Park East Road, Qingpu, Shanghai 201700, P.R. China E-mail: hongmeijinyx@163.com

Key words: glycated hemoglobin, microalbuminuria, serum cystatin $\mathrm{C}$, gestational diabetes mellitus, pregnancy outcome

\section{Introduction}

Gestational diabetes mellitus (GDM) is clinically classified as a high-risk pregnancy condition (1). In recent years, the incidence of GDM is increasing with continuous changes in living standards and eating habits (2). It has been estimated that 1 out of 15 pregnant females is susceptible to GDM, and in developed countries, including the US and the UK, the incidence of GDM exceeds $10 \%$. The uterus of patients with GDM has a high-glucose environment, which may exert long-term effects on the mother and fetus (3). GDM may greatly increase the incidence of complications during pregnancy, including polyhydramnios, eclampsia and premature delivery. More seriously, it may lead to abortion (4). In addition, the probability of fetal malformation and developmental limitation is markedly increased in patients with GDM. If the fetus remains in a high-glucose environment during pregnancy, it is prone to developing respiratory distress syndrome and hypoglycemia once delivered, which may be life-threatening to the infant (5). According to a survey, $24.84 \%$ of females with GDM developed GDM-associated diseases, including respiratory distress syndrome, organ dysplasia, following childbirth (6). Owing to the high incidence of GDM and high risk associated with it, the present study investigated methods which may facilitate effective clinical diagnosis and treatment of GDM. To date, no breakthrough has been achieved with this regard. Therefore, an increasing number of studies performed worldwide focus on the identification of effective indicators for pregnancy outcomes in patients with GDM, which may allow for the prevention and treatment of GDM. Studies have indicated that glycosylated hemoglobin (HbAlc) and urinary microalbuminuria (24 h mAlb) are closely associated with GDM (7-9), while serum cystatin C (Cys-C) is a highly sensitive indicator of renal impairment (10). In the present study, it was hypothesized that Cys-C may also be abnormally elevated in patients with GDM, and that detection of HbAlc, $24 \mathrm{~h}$ mAlb and Cys-C may be an effective predictor of pregnancy outcomes in patients with GDM. Therefore, a retrospective analysis of patients with GDM was conducted to provide support for future clinicians in the diagnosis and treatment of adverse pregnancy in patients with GDM.

\section{Materials and methods}

General information. A total of 144 pregnant females with GDM admitted to the Department of Obstetrics, Qingpu 
Branch, Zhongshan Hospital Affiliated to Fudan University (Shanghai, China) between August 2016 and September 2017, were selected for retrospective analysis. Their age ranged from 22 to 35 years, with an average of $27.12 \pm 4.93$ years. A further 117 cases of normal pregnancy (age, 22-34 years; average age, $26.83 \pm 4.62$ years) were selected as the control group. The experiment was approved by the Ethics Committee of Qingpu Branch, Zhongshan Hospital Affiliated to Fudan University (Shanghai, China) and all subjects provided written informed consent.

Inclusion and exclusion criteria. Criteria for inclusion were as follows: i) Pregnant women diagnosed with GDM via oral glucose tolerance test, in line with the 2016 GDM diagnostic guidelines (11); ii) Blood glucose $<7.0 \mathrm{mmol} / \mathrm{l}$; iii) delivery at the Zhongshan Hospital Affiliated to Fudan University; and iv) complete medical data. The exclusion criteria were as follows: i) Family history of genetic diabetes; ii) presence of a tumor; iii) mental illness; iv) cardio-cerebral vascular disease; v) severe liver and kidney dysfunction; vi) organ failure; vii) fetal congenital malformation diagnosed by B-ultrasound; viii) patients who were long-term bedridden; and ix) patients transferred from another hospital.

Collection of biological fluids and measurement of biomarkers. Pregnant women with GDM were classified as the GDM group and normal pregnant women were categorized as the control group. The 24-h urine samples were collected from 7 to 7 am the next day, and $10 \mathrm{ml}$ urine per sample was used. Following centrifugation for $5 \mathrm{~min}$ at $2,432 \times \mathrm{g}\left(20^{\circ} \mathrm{C}\right)$, the supernatant of the urine was obtained, and the 24-h urine $24 \mathrm{~h} \mathrm{mAlb}$ levels of the two groups were determined via the biuret method. In the morning, $5 \mathrm{ml}$ fasting venous blood was drawn from patients and centrifuged for $10 \mathrm{~min}$ at $2,432 \times \mathrm{g}\left(20^{\circ} \mathrm{C}\right)$. The serum in the supernatant was divided into two portions that were stored in a $-80^{\circ} \mathrm{C}$ refrigerator for testing. One portion was used to detect $\mathrm{HbAlc}$ levels with an automatic biochemical analyzer (AU5800; Beckman Coulter), while the other portion was used to detect $\mathrm{Cys}-\mathrm{C}$ levels via latex-enhanced immunoturbidimetric assay according to manufacturer's protocol (cat. no. UFWD0121; Shanghai Junrui Biotechnology Co., Ltd.) (12).

Observation indicators. The following information was collected: Maternal clinical information including age, body weight and gestational age; HbA1c level; Cys-C level; $24 \mathrm{~h}$ mAlb level; pregnancy outcome and adverse pregnancy rate; preterm birth (28-37 weeks pregnancy); premature rupture of membranes (progressive uterine cervix decline before delivery; cervical tube disappearance and fetal malposition decline); polyhydramnios (largest pocket depth of abdominal by ultrasound prior to delivery $\geq 8 \mathrm{~cm}$ or amniotic fluid volume after delivery $>2,000 \mathrm{ml}$; fetal distress (average 10-min fetal heart rate $>180$ or $<120$ beats/min); abnormal fetal development (body weight $<2,500 \mathrm{~g}$ for developmental obstruction, weight $>4,000 \mathrm{~g}$ for a huge infant). The correlations of HbAlc, Cys- $\mathrm{C}$ and $24 \mathrm{~h}$ mAlb with adverse pregnancy outcomes, including adverse pregnancy rates and neonatal Apgar scores [according to 2016 Newborn Apgar scoring standard (13)] were then determined.
Statistical analysis. The data were analyzed and processed using the SPSS 22.0 statistical package (IBM Corp.). Enumeration data, including the place of residence, lifestyle habits and adverse pregnancies, were expressed as rates. Comparisons between groups were performed using the chi-squared test. Continuous variables, including age, body weight and $\mathrm{HbA}_{1 \mathrm{c}}$ levels were expressed as the mean \pm standard deviation. The Independent Samples t-test was used for comparison of means. Correlation between HbAlc, Cys-C, mAlb and neonatal Apgar scores was analyzed by Pearson correlation coefficient; Logistic regression analysis was used to correlate HbAlc, Cys- $C, m A l b$ and adverse pregnancy outcomes. Predictive values were analyzed using receiver operating characteristic (ROC) curves. $\mathrm{P}<0.05$ was considered to indicate a statistically signficant difference.

\section{Results}

Comparison of clinical data. There was no difference in age, weight, gestational age, blood routine examination and the place of residence between the two groups $(\mathrm{P}>0.05)$, suggesting that the two groups were comparable (Table I).

Comparison of HbAlc, Cys-C and $24 \mathrm{~h} \mathrm{mAlb} \mathrm{levels.} \mathrm{The} \mathrm{level}$ of HbA1c of the GDM group $(8.56 \pm 0.42 \%)$ was significantly higher than that in the control group $(6.57 \pm 0.22 \% ; \mathrm{P}<0.001$; Fig. 1). The serum levels of Cys-C in the GDM group $(1.53 \pm 0.40 \mathrm{mg} / \mathrm{l})$ were significantly higher than those in the control group $(0.92 \pm 0.17 \mathrm{mg} / \mathrm{l} ; \mathrm{P}<0.001$; Fig. 2). Furthermore, the levels of $24 \mathrm{~h} \mathrm{mAlb}$ in the GDM group $(21.24 \pm 5.59 \mathrm{mg} / \mathrm{l})$ were significantly higher than those in the control group (16.69 \pm 4.27 mg/l; P<0.001; Fig. 3).

Comparison of adverse pregnancy rates. In the GDM group, the premature delivery rate was $9.03 \%$, the premature membrane rupture rate was $10.42 \%$, the polyhydramnios rate was $5.56 \%$, the fetal distress rate was $9.03 \%$ and the abnormal fetal development rate was $6.94 \%$. In the control group, the premature delivery rate was $5.13 \%$, the premature membrane rupture rate was $4.27 \%$, the polyhydramnios rate was $2.56 \%$, the fetal distress rate was $1.71 \%$ and the abnormal fetal developmental rate was $2.56 \%$. The rate of adverse pregnancy in the GDM group (40.97\%) was significantly higher than that in the control group $(16.24 \%$; $\mathrm{P}<0.001$; Table II).

Association of $\mathrm{HbAlc}, \mathrm{Cys}-\mathrm{C}$ and $24 \mathrm{~h} \mathrm{mAlb}$ with adverse pregnancy outcomes. Logistic regression analysis indicated that in maternal patients with GDM, but not in healthy pregnant women, HbA1c, Cys-C and $24 \mathrm{~h}$ mAlb were closely associated with adverse pregnancy outcomes $(\mathrm{P}<0.050)$ and were risk factors leading to adverse pregnancy outcomes in GDM (Table III).

Correlation between $\mathrm{HbA}_{l c}$, Cys-C, $24 \mathrm{~h} \mathrm{mAlb}$ and neonatal Apgar score. The Apgar score of the neonates in the GDM group was 7.12 \pm 1.07 . Linear correlation analysis indicated that $\mathrm{HbA} 1 \mathrm{c}, \mathrm{Cys}-\mathrm{C}$ and $24 \mathrm{~h}$ mAlb were negatively correlated with the neonatal Apgar score $(r=-0.509,-0.678$ and -0.733 , respectively; $\mathrm{P}<0.001$; Figs. 4-6). 
Table I. Comparison of general data between the two groups.

\begin{tabular}{lcccr}
\hline Parameter & GDM group $(\mathrm{n}=144)$ & Normal group $(\mathrm{n}=117)$ & $\mathrm{t}$ or $\chi^{2}$ & P-value \\
\hline Age (years) & $27.12 \pm 4.93$ & $26.83 \pm 4.62$ & 0.486 & 0.627 \\
Body weight $(\mathrm{kg})$ & $61.24 \pm 6.24$ & $60.55 \pm 6.51$ & 0.871 & 0.384 \\
Gestational week & $38.62 \pm 5.21$ & $39.27 \pm 5.84$ & 0.949 & 0.343 \\
WBC $\left(\times 10^{9} / \mathrm{l}\right)$ & $16.24 \pm 5.04$ & $16.81 \pm 4.86$ & 0.923 & 0.357 \\
RBC $\left(\mathrm{x} 10^{12} / \mathrm{l}\right)$ & $6.28 \pm 2.07$ & $5.94 \pm 2.44$ & 1.218 & 0.224 \\
PLT $\left(\times 10^{9} / \mathrm{l}\right)$ & $187.24 \pm 34.51$ & $194.53 \pm 29.85$ & 1.802 & 0.072 \\
Place of residence & & & 0.880 & 0.348 \\
Town & $81(56.25)$ & $59(50.43)$ & & 0.576 \\
Rural area & $63(43.75)$ & $58(49.57)$ & & \\
Primipara & & & & \\
Yes & $131(90.97)$ & $104(88.89)$ & & \\
No & $13(9.03)$ & $13(11.11)$ & & \\
\hline
\end{tabular}

Values are expressed as $\mathrm{n}(\%)$ or the mean \pm standard deviation. WBC, white blood cells; RBC, red blood cells; PLT, platelets; GDM, gestational diabetes mellitus.

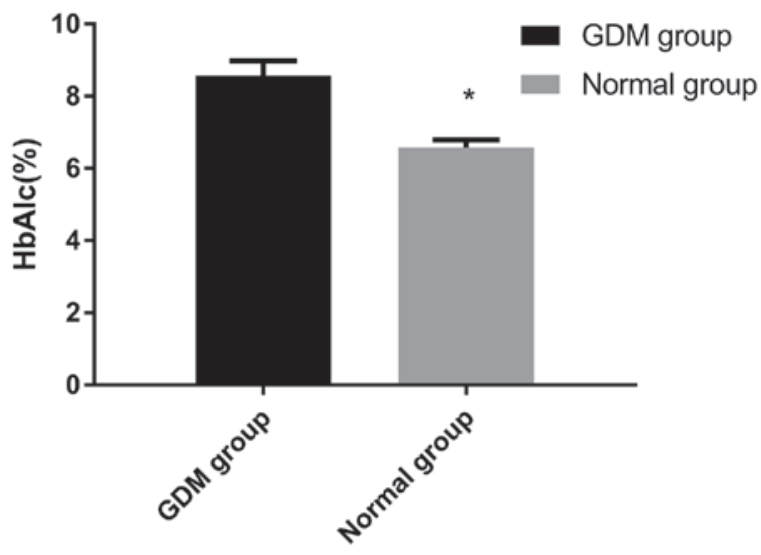

Figure 1. Comparison of HbAlc levels between the two groups. HbA1c levels were significantly higher in the GDM group than those in the control group. ${ }^{*} \mathrm{P}<0.001$ vs. GDM group. HbA1c, glycated hemoglobin; GDM, gestational diabetes mellitus.

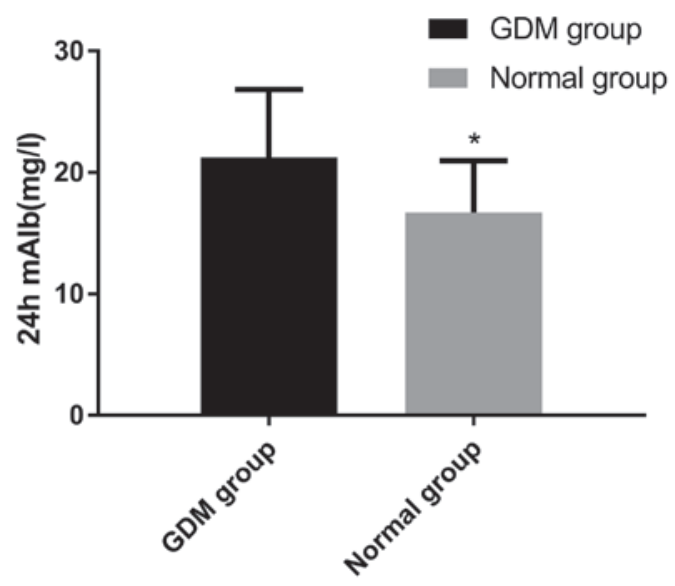

Figure 2. Comparison of Cys-C levels between the two groups. Cys-C levels were significantly higher in the GDM group than those in the control group. "P<0.001 vs. GDM group. Cys-C, cystatin C; GDM, gestational diabetes mellitus.

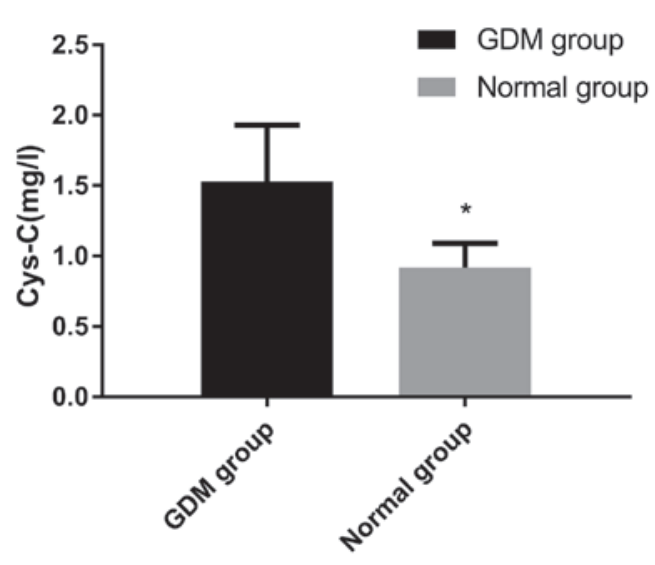

Figure 3. Comparison of $24 \mathrm{~h}$ mAlb levels between the two groups. The $24 \mathrm{~h}$ $\mathrm{mAlb}$ levels were significantly higher in the GDM group than those in the control group. ${ }^{*} \mathrm{P}<0.001$ vs. GDM group. $24 \mathrm{~h}$ mAlb, microalbuminuria; GDM, gestational diabetes mellitus.

Predictive value of HbAlc, Cys-C and $24 \mathrm{~h}$ mAlb regarding adverse pregnancy outcomes for patients with GDM. Binary logistic analysis was performed using $\mathrm{HbAlc}$, Cys-C, and $24 \mathrm{~h}$ $\mathrm{mAlb}$ as three independent variables to obtain joint predictive factors, using the following formula: $\log (\mathrm{P})$ value $=1.626+$ $0.051 \times \mathrm{HbAl}+0.426 \times$ Cys-C $+0.623 \times 24 \mathrm{~h}$ mAlb. According to ROC analysis, the predictive sensitivity of HbAlc, Cys-C and $24 \mathrm{~h} \mathrm{mAlb}$ for adverse pregnancy outcome was calculated to be $96.49 \%$ and the specificity was calculated to be 77.19\% (Fig. 7; Table IV).

\section{Discussion}

Pregnancy is a unique circumstance under which the female body undergoes certain physiological changes. Alterations in glucose metabolism are among the most significant physiological changes that occur during this process (14). The fasting blood glucose levels of the mother are generally 
Table II. Comparison of adverse pregnancy rates between the two groups.

\begin{tabular}{lcrr}
\hline Item & GDM group (n=144) & Normal group (n=117) & $\chi^{2}$ \\
\hline Premature birth & $13(9.03)$ & $6(5.13)$ & 1.454 \\
Premature rupture of membranes & $15(10.42)$ & $5(4.27)$ & 0.228 \\
Excessive amniotic fluid & $8(5.56)$ & $3(2.56)$ & 3.443 \\
Fetal intrauterine distress & $13(9.03)$ & $2(1.71)$ & 0.064 \\
Abnormal fetal development & $10(6.94)$ & $3(2.56)$ & 0.232 \\
Overall adverse pregnancy rate $(\%)$ & 40.97 & 16.24 & 0.012 \\
\end{tabular}

Values are expressed as $\mathrm{n}(\%)$ unless otherwise specified. GDM, gestational diabetes mellitus.

Table III. Correlation analysis between HbA1c, Cys-C and $24 \mathrm{~h}$ mAlb and adverse pregnancy rate in patients with GDM.

\begin{tabular}{lcccrr}
\hline Factor & Reference range & Hazards ratio & SE & B & 95\% CI \\
\hline HbAlc & $4-6 \%$ & 0.247 & 0.468 & 12.314 & $1.369-3.816$ \\
Cys-C & $0.51-1.09 \mathrm{mg} / \mathrm{dl}$ & 0.670 & 0.191 & 8.723 & $1.093-2.473$ \\
$24 \mathrm{~h} \mathrm{mAlb}$ & $<150 \mathrm{mg} / 24 \mathrm{~h}$ & 0.229 & 0.555 & 6.942 & $1.045-2.185$ \\
\hline
\end{tabular}

SE, standard error; HbA1c, glycated hemoglobin; CI, confidence interval; Cys-C, cystatin C; 24 h mAlb, microalbuminuria.

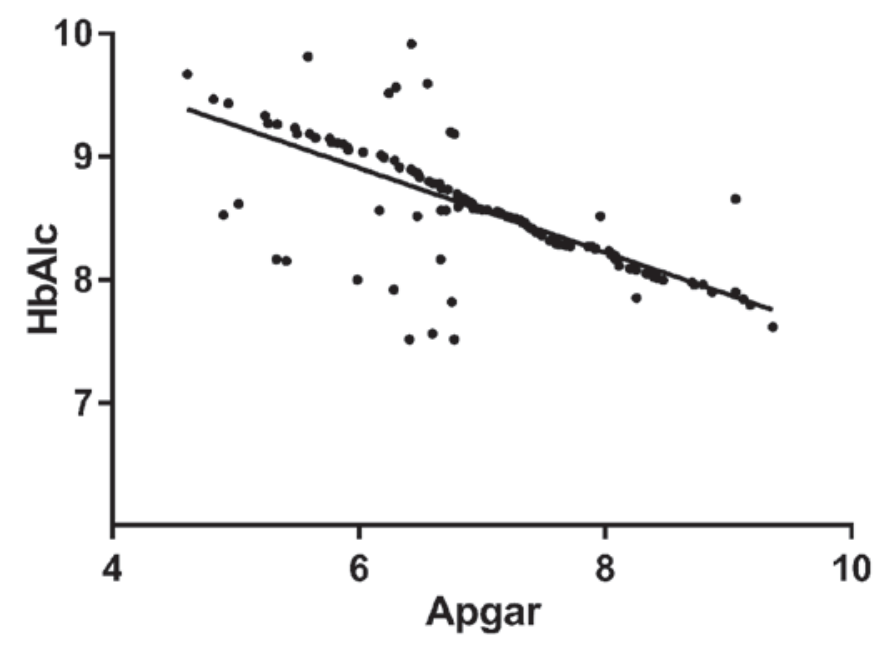

Figure 4. Correlation of HbAlc with neonatal Apgar scores in patients with GDM. Linear correlation analysis indicated that the level of $\mathrm{HbA} 1 \mathrm{c}$ was negatively correlated with the neonatal Apgar scores $(r=-0.509 ; \mathrm{P}<0.001)$. HbA1c, glycated hemoglobin.

reduced during pregnancy, and this is associated with a high incidence of GDM (15). The primary reason for the decrease in maternal blood glucose is that the fetus consumes a large amount of sugar during development, and insulin accelerates the release of glucose into the blood for metabolization, which then also decreases the blood sugar levels (16). It has been indicated that blood glucose metabolism in pregnant females is significantly lower compared with that in non-pregnant females. The key factor affecting maternal blood glucose is insulin, the sensitivity to which is significantly reduced during pregnancy (17). Therefore, in order to maintain normal functioning of the maternal body, accelerated secretion of insulin

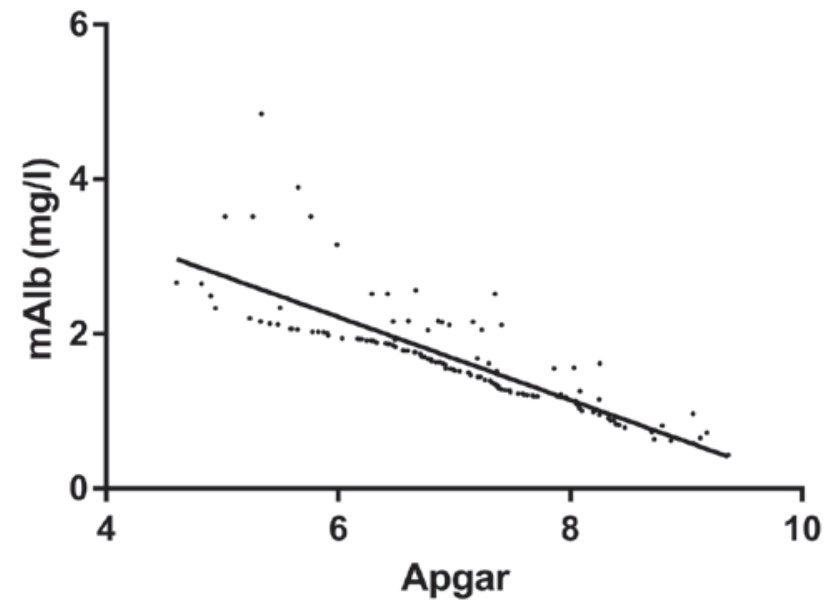

Figure 5. Correlation of $24 \mathrm{~h} \mathrm{mAlb}$ with neonatal Apgar score. Linear correlation analysis indicated a negative correlation between $24 \mathrm{~h} \mathrm{mAlb}$ and neonatal Apgar scores ( $\mathrm{r}=-0.954 ; \mathrm{P}<0.001) .24 \mathrm{~h} \mathrm{mAlb}$, microalbuminuria.

in pregnant females must be regulated. In pregnant females with impaired insulin secretion, smooth acceleration of insulin secretion may not be possible, leading to abnormal glucose metabolism and onset of GDM $(18,19)$. GDM is a high-risk disease during pregnancy. If the optimal treatment time is missed, GDM causes functional and environmental changes affecting fetal blood sugar metabolism, leading to a variety of adverse pregnancy outcomes (20). For GDM, clinical treatment is essentially according to the principle 'early detection, early treatment'. At present, HbAlc remains the gold standard for monitoring blood sugar function. The formation rate of $\mathrm{HbA} 1 \mathrm{c}$, which is produced by the interaction of hemoglobin and carbohydrates, and the blood glucose concentration are positively correlated $(20,21)$. Therefore, detection of HbA1c 


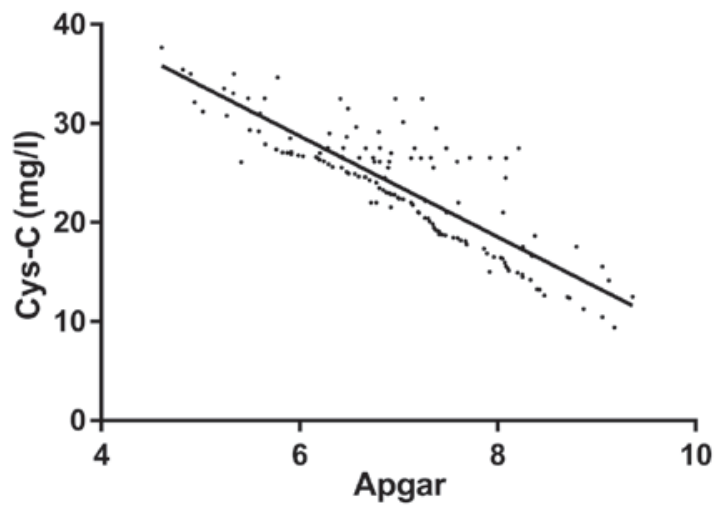

Figure 6. Correlation between serum Cys-C and neonatal Apgar scores. Linear correlation analysis indicated that the level of Cys-C was negatively correlated with the neonatal Apgar score $(\mathrm{r}=-0.954 ; \mathrm{P}<0.001)$. Cys-C, cystatin $\mathrm{C}$.

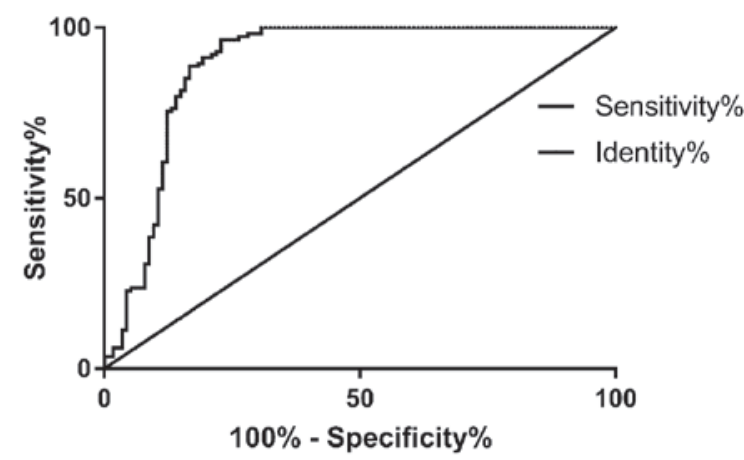

Figure 7. Predictive value of maternal HbAlc, Cys-C and $24 \mathrm{~h}$ mAlb for adverse pregnancy outcomes in patients with GDM. According to logistic regression analysis, the combined predictive sensitivity of HbAlc, Cys-C and $24 \mathrm{~h} \mathrm{mAlb}$ in pregnant females for adverse pregnancy outcomes was $96.49 \%$ and the specificity was $77.19 \%$.

in the clinic may reflect simple blood glucose levels during pregnancy and facilitate the identification of the development of GDM. $24 \mathrm{~h} \mathrm{mAlb}$ and Cys-C are sensitive indicators of renal injury and serve as important reference points for glomerular microangiopathy in females with GDM (22). To date, only a few associated reference studies between GDM pregnancy outcomes and HbAlc, Cys-C and $24 \mathrm{~h} \mathrm{mAlb}$ have been performed $(23,24)$. Therefore, the present study aimed to establish maternal HbA1c, Cys-C and $24 \mathrm{~h} \mathrm{mAlb}$ as predictors of pregnancy outcomes in subjects with GDM.

The results of the present study demonstrated that the levels of HbA1c, Cys-C and $24 \mathrm{~h}$ mAlb in the GDM group were significantly higher than those in the control group, which is consistent with the results of Chawla and Malik (25). The significantly increased level of $24 \mathrm{~h} \mathrm{mAlb}$ in the GDM group was attributed to an increase in blood volume, renal blood flow and the glomerular filtration rate during pregnancy, which markedly increased urinary protein excretion. In addition, a high-glucose environment is always present in patients with GDM. In these subjects, endothelial cells promote the release of vasoactive substances, thus altering plasma protein filtration in the glomerular basement membrane. They exhibited a large amount of protein in the blood circulation which were leaked into the urine. Females with normal pregnancies did not exhibit a significant increase in $24 \mathrm{~h}$ mAlb, whereas patients
Table IV. Predictive value of maternal HbAlc, Cys-C and $24 \mathrm{~h}$ mAlb combined for adverse pregnancy outcomes.

\begin{tabular}{lc}
\hline Variable & Numerical value \\
\hline AUC & 0.891 \\
Standard deviation & 0.024 \\
$95 \%$ CI & $0.843-0.939$ \\
Cut-off $(\mathrm{ng} / \mathrm{ml})$ & 1.249 \\
Sensitivity (\%) & 96.49 \\
Specificity (\%) & 77.19 \\
P-value & $<0.001$
\end{tabular}

HbA1c, glycated hemoglobin; Cys-C, cystatin C; CI, confidence interval; $24 \mathrm{~h} \mathrm{mAlb}$, microalbuminuria; AUC, area under the receiver operating characteristic curve.

with GDM had a significantly increased $24 \mathrm{~h}$ mAlb expression, suggesting that $24 \mathrm{~h} \mathrm{mAlb}$ may be used as an effective indicator of glomerular damage. Cys-C is a low-molecular, non-glycosylated protein, consisting of 122 amino acids residues, which is cleared by the kidneys, resulting in low levels in normal individuals (26). However, impaired kidney function reduces the clearance rate of $\mathrm{Cys}-\mathrm{C}$, resulting in high plasma levels. A mother and her fetus are intimately connected during pregnancy, and any abnormal condition in the mother influences the fetus to varying degrees. In the present study, the adverse pregnancy rate in the GDM group was significantly higher than that in the control group, and it was suggested that HbA1c, Cys-C and $24 \mathrm{~h}$ mAlb may be used as indicators for predicting pregnancy outcomes in pregnant females. The major cause for the association of HbAlc, Cys-C and $24 \mathrm{~h} \mathrm{mAlb}$ with the pregnancy outcome is presumed to be blood glucose. Abnormal glucose metabolism in the mother and high insulin levels in the long-term high-glucose fetal environment activate the amino acid transfer system, which greatly increases the synthetic ability of proteins. However, fat disintegration is reduced, resulting in the accumulation of a large amount of fat and glucose in the fetal tissues, leading to various developmental dysfunctions in the neonate. At the same time, due to the high permeability of the uterus between the mother and fetus, their blood sugar levels may increase with the mother (27). Stimulation by high glucose destroys blood vessel walls, causing spasms. Capillary stenosis in the placenta causes narrowing of the vascular lumen, thereby considerably reducing hemodynamics and causing a shortage of blood supply to the fetus, which may lead to several fetal issues. In the present study, HbA1c, Cys-C and $24 \mathrm{~h} \mathrm{mAlb}$ were negatively correlated with the neonatal Apgar scores in patients with GDM, suggesting that combined HbAlc, Cys-C and $24 \mathrm{~h}$ mAlb reading can be used to predict the outcome of delivery in GMD patients. ROC analysis indicated that HbAlc, Cys-C and $24 \mathrm{~h}$ mAlb levels of pregnant females with GDM have a relatively high sensitivity and specificity for predicting adverse pregnancy outcomes, suggesting that future clinical trials may determine pregnancy outcomes by detecting the levels of these indicators to provide protective intervention as early as possible. 
Of note, the present study does contain certain limitations. Effective data analyses of other types of high-risk pregnancies was not possible, as the experimental population was relatively small. The age range of the study subjects was relatively narrow, and it may not be excluded that HbAlc, Cys-C and $24 \mathrm{~h} \mathrm{mAlb}$ are different in pregnant females of different ages and geographical regions. In addition, due to the short experimental period, it was impossible to determine the association of HbAlc, Cys-C and $24 \mathrm{~h} \mathrm{mAlb}$ with the prognosis of GDM-associated health conditions in the mothers after pregnancy. In the future, a more detailed follow-up of the subjects will be performed and the number of subjects will be increased to obtain the best possible experimental results.

In conclusion, the present study indicated that $\mathrm{HbAlc}$, Cys-C and $24 \mathrm{~h} \mathrm{mAlb}$ are elevated in females with GDM, and may be effective indicators of adverse outcomes of high-risk pregnancies.

\section{Acknowledgements}

Not applicable.

\section{Funding}

No funding was received.

\section{Availability of data and materials}

The datasets used and/or analyzed during the current study are available from the corresponding author on reasonable request.

\section{Author's contribution}

HJ conceived and designed the study and interpreted the results, analyzed the data, prepared the figures, drafted, edited and revised manuscript.

\section{Ethics approval and consent to participate}

The study was approved by the Ethics Committee of Qingpu Branch, Zhongshan Hospital Affiliated to Fudan University (Shanghai, China) and all subjects provided written informed consent.

\section{Patient consent for publication}

Not applicable.

\section{Competing interests}

The author declare that she has no competing interests.

\section{References}

1. Spaight C, Gross J, Horsch A and Puder JJ: Gestational diabetes mellitus. Endocr Dev 31: 163-178, 2016.

2. Euser AG, Hammes A, Ahrendsen JT, Neshek B, Weitzenkamp DA, Gutierrez J, Koivunen P, Julian CG and Moore LG: Gestational diabetes prevalence at moderate and high altitude. High Alt Med Biol 19: 367-372, 2018.

3. Senat MV and Deruelle P: Gestational diabetes mellitus. Gynecol Obstet Fertil 44: 244-247, 2016 (In French).
4. Damm P, Houshmand-Oeregaard A, Kelstrup L, Lauenborg J, Mathiesen ER and Clausen TD: Gestational diabetes mellitus and long-term consequences for mother and offspring: A view from Denmark. Diabetologia 59: 1396-1399, 2016.

5. Schoenaker DA, Mishra GD, Callaway LK and SoedamahMuthu SS: The role of energy, nutrients, foods, and dietary patterns in the development of gestational diabetes mellitus: A systematic review of observational studies. Diabetes Care 39: 16-23, 2016.

6. Lu M, Xu Y, Lv L and Zhang M: Association between vitamin $\mathrm{D}$ status and the risk of gestational diabetes mellitus: A meta-analysis. Arch Gynecol Obstet 293: 959-966, 2016.

7. Rudland VL, Hinchcliffe M, Pinner J, Cole S, Mercorella B, Molyneaux L, Constantino M, Yue DK, Ross GP and Wong J: Identifying glucokinase monogenic diabetes in a multiethnic gestational diabetes mellitus cohort: New pregnancy screening criteria and utility of HbA1c. Diabetes Care 39: 50-52, 2016.

8. Baack ML, Forred BJ, Larsen TD, Jensen DN, Wachal AL, Khan MA and Vitiello PF: Consequences of a maternal high-fat diet and late gestation diabetes on the developing rat lung. PLoS One 11: e0160818, 2016.

9. Sherwani SI, Khan HA, Ekhzaimy A, Masood A and Sakharkar MK: Significance of HbAlc test in diagnosis and prognosis of diabetic patients. Biomark Insights 11: 95-104, 2016.

10. Pottel H, Delanaye P, Schaeffner E, Dubourg L, Eriksen BO, Melsom T, Lamb EJ, Rule AD, Turner ST and Glassock RJ: Estimating glomerular filtration rate for the full age spectrum from serum creatinine and cystatin C. Nephrol Dial Transplant 32: 497-507, 2017.

11. Zhu Y and Zhang C: Prevalence of gestational diabetes and risk of progression to type 2 diabetes: A global perspective. Curr Diab Rep 16: 7, 2016.

12. Dipalo M, Buonocore R, Gnocchi C, Picanza A, Aloe R and Lippi G: Analytical evaluation of Diazyme procalcitonin (PCT) latex-enhanced immunoturbidimetric assay on Beckman Coulter AU5800. Clin Chem Lab Med 53: 593-597, 2015.

13. Ray JG, Medcalf KE and Park AL: Association of newborn Apgar score with maternal admission to the intensive care unit. JAMA Pediatr 170: 88-89, 2016.

14. Rani PR and Begum J: Screening and diagnosis of gestational diabetes mellitus, where do we stand. J Clin Diagn Res 10: QE01-QE04, 2016.

15. Sovio U, Murphy HR and Smith GC: Accelerated fetal growth prior to diagnosis of gestational diabetes mellitus: A prospective cohort study of nulliparous women. Diabetes Care 39: 982-987, 2016.

16. Nahum Sacks K, Friger M, Shoham-Vardi I, Abokaf H, Spiegel E, Sergienko R, Landau D and Sheiner E: Prenatal exposure to gestational diabetes mellitus as an independent risk factor for long-term neuropsychiatric morbidity of the offspring. Am J Obstet Gynecol 215: 380.e1-7, 2016.

17. Muralimanoharan S, Maloyan A and Myatt L: Mitochondrial function and glucose metabolism in the placenta with gestational diabetes mellitus: Role of miR-143. Clin Sci (Lond) 130: 931-941, 2016.

18. Retnakaran R and Shah BR: Role of type 2 diabetes in determining retinal, renal, and cardiovascular outcomes in women with previous gestational diabetes mellitus. Diabetes Care 40: 101-108, 2017.

19. Marso SP, Bain SC, Consoli A, Eliaschewitz FG, Jódar E, Leiter LA, Lingvay I, Rosenstock J, Seufert J, Warren ML, et al: Semaglutide and cardiovascular outcomes in patients with type 2 diabetes. N Engl J Med 375: 1834-1844, 2016.

20. Karges B, Kapellen T, Wagner VM, Steigleder-Schweiger C, Karges W, Holl RW and Rosenbauer J; DPV Initiative: Glycated hemoglobin Alc as a risk factor for severe hypoglycemia in pediatric type 1 diabetes. Pediatr Diabetes 18: 51-58, 2017.

21. Faruque LI, Wiebe N, Ehteshami-Afshar A, Liu Y, Dianati-Maleki N, Hemmelgarn BR, Manns BJ and Tonelli M; Alberta Kidney Disease Network: Effect of telemedicine on glycated hemoglobin in diabetes: A systematic review and meta-analysis of randomized trials. CMAJ 189: E341-E364, 2017.

22. Lau L, Al-Ismaili Z, Harel-Sterling M, Pizzi M, Caldwell JS, Piccioni M, Lands LC, Mottes T, Devarajan P, Goldstein SL, et al: Serum cystatin C for acute kidney injury evaluation in children treated with aminoglycosides. Pediatr Nephrol 32: 163-171, 2017. 
23. Hughes RC, Moore MP, Gullam JE, Mohamed K and Rowan J: An early pregnancy $\mathrm{HbAlc} \geq 5.9 \%(41 \mathrm{mmol} / \mathrm{mol})$ is optimal for detecting diabetes and identifies women at increased risk of adverse pregnancy outcomes. Diabetes Care 37: 2953-2959, 2014.

24. Qiu X, Qiu Y, Dai Y, et al: A research of correlation between renal damage of patients with gestational diabetes mellitus and level of serum cystatin C. International Journal of Laboratory Medicine 10: 1289-1290, 2014.

25. Chawla R and Malik S: Microalbuminuria detected at mid term as a marker for adverse pregnancy outcome. Int J Health Sci Res 8: 41-52, 2018.
26. Bargnoux AS,PiéroniL,Cristol JP,KusterN,DelanayeP,CarlierMC, Fellahi S, Boutten A, Lombard C, González-Antuña A, et al: Multicenter evaluation of cystatin $\mathrm{C}$ measurement after assay standardization. Clin Chem 63: 833-841, 2017.

27. Fitzpatrick KE, Tuffnell D, Kurinczuk JJ and Knight M: Incidence, risk factors, management and outcomes of amniotic-fluid embolism: A population-based cohort and nested case-control study. BJOG 123: 100-109, 2016.

cC) (i) $(9$ This work is licensed under a Creative Commons International (CC BY-NC-ND 4.0) License. 